\title{
Crescimento e produtividade de duas cultivares de feijão em função de doses de ácido 2,3,5-triiodobenzoico
}

\author{
Growth and yield of two common bean cultivars \\ as affected by 2,3,5-triiodobenzoic acid rates
}

\author{
Rogério Peres Soratto ${ }^{{ }^{*}}$ Genivaldo David de Souza-Schlick ${ }^{\mathrm{II}}$ \\ Adalton Mazetti Fernandes ${ }^{\mathrm{III}}$ Luís Fernando Fontana Antunes de Oliveira ${ }^{\mathrm{I}}$
}

\section{RESUMO}

O crescimento excessivo da parte aérea do feijoeiro pode aumentar o acamamento das plantas e promover fechamento muito rápido da cultura, limitando a produtividade de grãos. O uso de reguladores de crescimento, como o ácido 2,3,5-triiodobenzoico (TIBA), pode reduzir o crescimento das plantas, porém, não existem informações sobre o uso dessa tecnologia na cultura do feijão. Objetivou-se com este trabalho avaliar o efeito de doses de TIBA (0, 8, 16, 32, 64 e $128 \mathrm{~g}$ do i.a. ha $\left.\mathrm{s}^{-1}\right)$ sobre o crescimento e a produtividade de grãos de duas cultivares de feijão ('IAC Alvorada' e 'IAC Jabola'). O delineamento experimental foi $o$ de blocos ao acaso, em esquema de parcelas subdivididas, com quatro repetições. A aplicação de TIBA reduziu o comprimento da maior haste de ambas as cultivares, até a dose média estimada de $100 \mathrm{~g} \mathrm{ha} \mathrm{g}^{-1}$ de TIBA. A altura de inserção da primeira vagem foi reduzida apenas na cultivar IAC Alvorada até a dose de $88 \mathrm{~g} \mathrm{ha} \mathrm{h}^{-1}$ de TIBA. A aplicação de TIBA reduziu em 10\% o número de grãos por vagem. A utilização de TIBA não afetou a produtividade de grãos, sendo uma alternativa para diminuir o porte das plantas de feijão.

Palavras-chave: Phaseolus vulgaris, regulador de crescimento, altura de plantas, componentes da produção.

\section{ABSTRACT}

The excessive aboveground growth of common bean can increase plant lodging and promote very rapid canopy closing, limiting grain yield. The use of growth regulators, such as 2,3,5-triiodobenzoic acid (TIBA), can reduce plant growth, however, there is no information on the use of this technology in the common bean crop. The objective of this study was to evaluate the effect of TIBA rates $\left(0,8,16,32,64\right.$, and $128 \mathrm{~g}$ a.i. ha $\left.a^{-1}\right)$ on growth and grain yield of two common bean cultivars ('IAC Alvorada' and 'IAC Jabola'). The experimental design used was randomized blocks, in a split plot scheme, with four replications.
The application of TIBA reduced the stem length of both cultivars, to the average estimated rate of $100 \mathrm{~g} \mathrm{ha}^{-1} \mathrm{TIBA}$. Height of insertion of the first pod was reduced only in IAC Alvorada up to rate of 88 $g \mathrm{ha}^{-1}$ TIBA. Application of TIBA reduced by $10 \%$ the number of grains per pod. The use of TIBA did not affect grain yield, being an alternative to reduce the size of the common bean plants.

Key words: Phaseolus vulgaris, growth regulators, plant height, yield components.

\section{INTRODUÇÃO}

O feijão (Phaseolus vulgaris L.) é uma das principais fontes de alimento da população brasileira além de compor os sistemas agrícolas de produção de grãos na região Centro-Sul do Brasil. No entanto, a busca por aumento de produtividade nessa cultura, muitas vezes, através do uso de maior quantidade de fertilizantes têm resultado na obtenção de plantas com maior vigor vegetativo (KOLKMAN \& KELLY, 2002), contribuindo para o aumento do índice de acamamento das plantas (SOUZA et al., 2010) e fechamento mais rápido da cultura. Em decorrência desses fatos, pode-se aumentar a incidência de doenças (KOLKMAN \& KELLY, 2002), limitar a produtividade (VALÉRIO et al., 1999) e prejudicar a qualidade dos grãos, além de dificultar a colheita mecanizada (SILVA et al., 2008).

Uma das práticas culturais que poderia minimizar esse problema e melhorar o desempenho

\footnotetext{
IDepartamento de Produção e Melhoramento Vegetal, Faculdade de Ciências Agronômicas (FCA), Universidade Estadual Paulista (UNESP), CP 237, 18610-307, Botucatu, SP, Brasil. E-mail: soratto@fca.unesp.br. *Autor para correspondência.

IIInstituto Federal de Educação, Ciência e Tecnologia de Mato Grosso do Sul (IFMS), Ponta Porã, MS, Brasil.

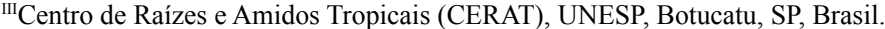


da cultura do feijoeiro é a aplicação de reguladores de crescimento (SOUZA et al., 2010; FERREIRA et al., 2013), com o objetivo de reduzir o crescimento excessivo da parte aérea, sem prejudicar a produtividade de grãos (RADEMACHER, 2000; SOUZA et al., 2010; ANDRADE et al., 2013). Sabese que a redução no crescimento apical das plantas pode aumentar a ramificação e, consequentemente, o número de vagens por planta, culminado em maior produtividade de grãos (ANDRADE et al., 2013), em função da melhor distribuição da matéria seca (MS) dos ramos para os grãos (GITTI et al., 2012).

Alguns produtos com capacidade de reduzir o crescimento vegetativo das plantas têm sido estudados na cultura do feijão, tais como os reguladores de crescimento cloreto de mepiquat, cloreto de clormequat, cloreto de clorocolina, etiltrinexapac (SOUZA et al., 2010), paclobutrazol (GITTI et al., 2012) e o fungicida propiconazol (ANDRADE et al., 2013). Porém, até o momento, foi demonstrado cientificamente apenas que o cloreto de clorocolina é capaz de reduzir o porte do feijoeiro sem diminuir a produtividade de grãos (SOUZA et al., 2010).

$\mathrm{O}$ ácido 2,3,5-triiodobenzoico (TIBA) é um regulador de crescimento que inibe o transporte polar basípeto da auxina, hormônio responsável pela dominância apical, por competir com este hormônio pelo mesmo sítio de ligação nas proteínas transportadoras, localizadas na membrana plasmática (GELDNER et al., 2001; CATO \& CASTRO, 2006). Este regulador de crescimento tem sido eficiente em reduzir a altura de plantas de soja (BURTON \& CURLEY, 1966; HICKS et al., 1967; WAX \& PENDLETON, 1968; BASTIDAS \& BUITRAGO, 1972; TANNER \& AHMED, 1974; CATO \& CASTRO, 2006), podendo ter efeitos semelhantes na cultura do feijão. Contudo, como nos trabalhos com soja têm se observado que as cultivares respondem de forma diferente à aplicação de TIBA (WAX \& PENDLETON, 1968; BASTIDAS \& BUITRAGO, 1972), pode ser que no feijoeiro também haja variações entre cultivares na resposta à aplicação desse regulador.

Dessa forma, objetivou-se com este trabalho avaliar o efeito de doses do regulador de crescimento TIBA no crescimento e a produtividade de grãos das cultivares de feijão 'IAC Alvorada' e 'IAC Jabola'.

\section{MATERIAL E MÉTODOS}

O experimento foi conduzido na Fazenda Experimental Lageado da Faculdade de Ciências Agronômicas - UNESP, município de Botucatu, SP
( $22^{\circ} 51^{\prime} \mathrm{S} ; 48^{\circ} 26^{\prime} \mathrm{W}$ e altitude de $\left.740 \mathrm{~m}\right)$. O solo da área é um Nitossolo Vermelho distroférrico (SANTOS et al., 2006). Antes da instalação do experimento, foram coletadas amostras de solo da área experimental na profundidade de $0-0,20 \mathrm{~m}$ e analisadas quimicamente (RAIJ et al., 2001). Os resultados foram: matéria orgânica, 37,6g dm${ }^{-3}$; $\mathrm{pH}\left(\mathrm{CaCl}_{2}\right), 5,0 ; \mathrm{P}$ (resina), $20,7 \mathrm{mg} \mathrm{dm}^{-3} ; \mathrm{K}, 2,1 \mathrm{mmol}_{\mathrm{c}} \mathrm{dm}^{-3} ; \mathrm{Ca}, 26,3 \mathrm{mmol}_{\mathrm{c}}$ $\mathrm{dm}^{-3} ; \mathrm{Mg}, 11,9 \mathrm{mmol}_{\mathrm{c}} \mathrm{dm}^{-3} ;{ }^{\mathrm{c}} \mathrm{CTC}, 75,8 \mathrm{mmol}_{\mathrm{c}} \mathrm{dm}^{-3} \mathrm{e}^{\mathrm{c}}$ saturação por bases de $53 \%$.

O experimento foi instalado no delineamento experimental de blocos ao acaso, em esquema de parcelas subdivididas, com quatro repetições. As parcelas foram constituídas por duas cultivares de feijão ('IAC Alvorada' e 'IAC Jabola') e as subparcelas por seis doses de $\operatorname{TIBA}(0,8,16,32$, 64 e $128 \mathrm{~g}$ do i.a. ha $^{-1}$ ). Cada parcela foi constituída por 5 linhas de $30 \mathrm{~m}$ de comprimento, espaçadas de $0,45 \mathrm{~m}$. Já as subparcelas foram compostas de 5 linhas com $5 \mathrm{~m}$ de comprimento. Para as avaliações, foram consideradas as três linhas centrais de cada subparcela, desprezando-se $0,5 \mathrm{~m}$ em ambas as extremidade de cada linha.

A cultivar 'IAC Alvorada' tem hábito de crescimento indeterminado semiereto (tipo III) e ciclo médio de 92 dias (CARBONELL et al., 2008). A cultivar 'IAC Jabola' também apresenta hábito de crescimento indeterminado semiereto, porém com plantas mais compactas (tipo II), com guias longas e ciclo médio de 96 dias (CHIORATO et al., 2009). A aplicação das doses de TIBA foi realizada quando as plantas estavam na fase de $\mathrm{V}_{4-7}$ (sete folhas trifolioladas totalmente expandidas), aos 30 dias após a emergência (DAE). Para a aplicação, foi utilizado pulverizador manual pressurizado com $\mathrm{CO}_{2}$, calibrado com uma vazão de $200 \mathrm{~L} \mathrm{ha}^{-1}$ de calda.

A semeadura foi realizada mecanicamente no sistema plantio direto, sobre palhada de milheto, no dia 10/03/2011, utilizando-se o espaçamento de $0,45 \mathrm{~m}$ e 15 sementes por metro de sulco. A adubação de semeadura foi realizada com base na análise de solo e nas recomendações de AMBROSANO et al. (1997), aplicando-se $200 \mathrm{~kg} \mathrm{ha}^{-1}$ da fórmula - NPK 08-28-16. A emergência das plantas ocorreu em 16/03/2011. A adubação de $\mathrm{N}$ em cobertura foi realizada aos 20 DAE, quando as plantas encontravam-se no estádio $\mathrm{V}_{4-4}$, aplicando-se $100 \mathrm{~kg}$ de $\mathrm{N}$, na forma de sulfato de amônio. Durante o período de condução do experimento, foram realizados todos os tratos culturais recomendados para a cultura.

Aos 60 DAE, foi coletada a parte aérea de 10 plantas ao acaso de cada subparcela, nas quais determinou-se a área foliar, utilizando medidor 
eletrônico LI-3100C. Em seguida, avaliou-se o comprimento da maior haste de cada planta, mediante a determinação da distância entre o colo da planta e a extremidade mais alta da planta. Posteriormente, a parte aérea das plantas foi submetida à secagem em estufa de circulação forçada de ar a $65^{\circ} \mathrm{C}$ por $96 \mathrm{~h}$; e pesada para a determinação da MS da parte aérea.

Por ocasião da colheita, realizada aos 96 DAE para ambas as cultivares, foram coletadas 10 plantas de cada subparcela. Nessas plantas, determinou-se a altura de inserção da primeira vagem, avaliada pela distância entre o colo da planta e o ponto de inserção da primeira vagem. Os números de ramos e de vagens por planta foram obtidos por meio de contagem em cada uma das plantas. Em seguida, as vagens foram debulhadas e os grãos foram contados e pesados para a obtenção do número de grãos por vagem e da massa de 100 grãos. Em duas fileiras da área útil de cada subparcela, determinouse a população final de plantas. Essas fileiras de plantas foram arrancadas, deixadas para secar ao sol e submetidas à trilha mecânica. Os grãos obtidos foram pesados para a determinação da produtividade de grãos e os valores foram expressos em $\mathrm{kg} \mathrm{ha}^{-1}(0,13 \mathrm{~kg}$ $\mathrm{kg}^{-1}$ de umidade).

Os dados obtidos foram submetidos à análise de variância. As médias das cultivares foram comparadas pelo teste $\mathrm{t}(\mathrm{DMS})(\mathrm{P} \leq 0,05)$ e os efeitos das doses de TIBA foram avaliados por análise de regressão $(\mathrm{P} \leq 0,05)$.

\section{RESULTADOS E DISCUSSÃO}

O comprimento da maior haste foi afetado pela interação cultivar $\mathrm{x}$ dose (Tabela 1). Houve redução no comprimento da maior haste das cultivares 'IAC Alvorada' e 'IAC Jabola' até as doses de 96 e $112 \mathrm{~g} \mathrm{ha}^{-1}$ de TIBA, respectivamente (Figura 1a). No entanto, apenas nas doses acima de $32 \mathrm{~g} \mathrm{ha}^{-1}$ de TIBA, as hastes da cultivar 'IAC Alvorada' tornaram-se menores que as da cutivar 'IAC Jabola'. A redução no comprimento da haste da cultivar 'IAC Alvorada' com a aplicação de TIBA chegou a $57 \mathrm{~cm}$, mas, na cultivar 'IAC Jabola', não ultrapassou os $28 \mathrm{~cm}$, o que demonstra que as cultivares responderam de forma diferente à aplicação de TIBA. Estudos mostraram que cultivares de soja apresentaram comportamento semelhante à aplicação de TIBA (WAX \& PENDLETON, 1968; BASTIDAS \& BUITRAGO, 1972). Com a diminuição no porte das plantas, pode-se aumentar a aeração da cultura e beneficiar a aplicação de defensivos agrícolas (GITTI et al., 2012). Esses mesmos autores obtiveram redução de até $21 \mathrm{~cm}$ no comprimento da maior haste das plantas de feijão da cultivar 'IPR Juriti' com a aplicação de paclobutrazol, um inibidor da síntese de giberelina. Já para CATO \& CASTRO (2006), em soja, a aplicação de TIBA reduziu em até $95 \mathrm{~cm}$ a altura das plantas.

Aárea foliar e a MS da parte aérea sofreram influência apenas do fator cultivar (Tabela 1), ou seja, a aplicação de TIBA diminuiu o comprimento das hastes sem interferir na área foliar e na produção de MS das plantas de feijão, o que é desejável no sistema de cultivo atual, em que se buscam plantas de menor porte, com arquitetura mais equilibrada $\mathrm{e}$ com capacidade de suportar maior número de vagens e grãos até o momento da colheita (SINGH, 2001; SOUZA et al., 2010). Em soja, a aplicação de TIBA também modificou a arquitetura das plantas, uma vez que esse regulador diminuiu o crescimento vegetativo

Tabela 1 - Características de crescimento, componentes da produção e produtividade de grãos de cultivares de feijão em resposta a doses de TIBA e análise de variância.

\begin{tabular}{|c|c|c|c|c|c|}
\hline \multirow{2}{*}{ Variável analisada } & \multicolumn{5}{|c|}{ 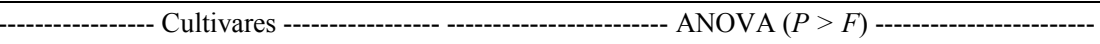 } \\
\hline & 'IAC Alvorada' & 'IAC Jabola' & Cultivar (C) & Dose (D) & $\mathrm{C} \times \mathrm{D}$ \\
\hline Comprimento da maior haste $(\mathrm{cm})$ & 79,1 & 86,9 & 0,079 & $<0,001$ & $<0,001$ \\
\hline Área foliar $\left(\mathrm{cm}^{2}\right.$ planta $\left.{ }^{-1}\right)$ & $1.471 \mathrm{~b}$ & $1.747 \mathrm{a}$ & 0,008 & 0,356 & 0,883 \\
\hline MS da parte aérea $\left(\mathrm{g}_{\text {planta }}{ }^{-1}\right)$ & $22,5 b$ & $31,7 \mathrm{a}$ & 0,005 & 0,082 & 0,201 \\
\hline Altura de inserção da $1^{\mathrm{a}}$ vagem $(\mathrm{cm})$ & 19,3 & 13,9 & 0,002 & 0,008 & 0,006 \\
\hline Número de ramos por planta & $1,9 \mathrm{~b}$ & $3,6 a$ & $<0,001$ & 0,515 & 0,248 \\
\hline População final (plantas ha ${ }^{-1}$ ) & $257.204 \mathrm{a}$ & $195.084 b$ & $<0,001$ & 0,070 & 0,074 \\
\hline Número de vagem por planta & $11,9 \mathrm{a}$ & $12,4 \mathrm{a}$ & 0,751 & 0,913 & 0,949 \\
\hline Número de grão por vagem & $4,0 \mathrm{a}$ & $3,9 \mathrm{a}$ & 0,058 & 0,040 & 0,950 \\
\hline Massa de 100 grão $(\mathrm{g})$ & $32,0 \mathrm{~b}$ & $42,2 \mathrm{a}$ & $<0,001$ & 0,784 & 0,887 \\
\hline Produtividade de grão $\left(\mathrm{kg} \mathrm{ha}^{-1}\right)$ & $3.339 \mathrm{a}$ & $3.148 \mathrm{a}$ & 0,313 & 0,469 & 0,993 \\
\hline
\end{tabular}

Médias seguidas de letras iguais nas linhas não diferem entre si pelo teste t (DMS) a 5\% de probabilidade. 


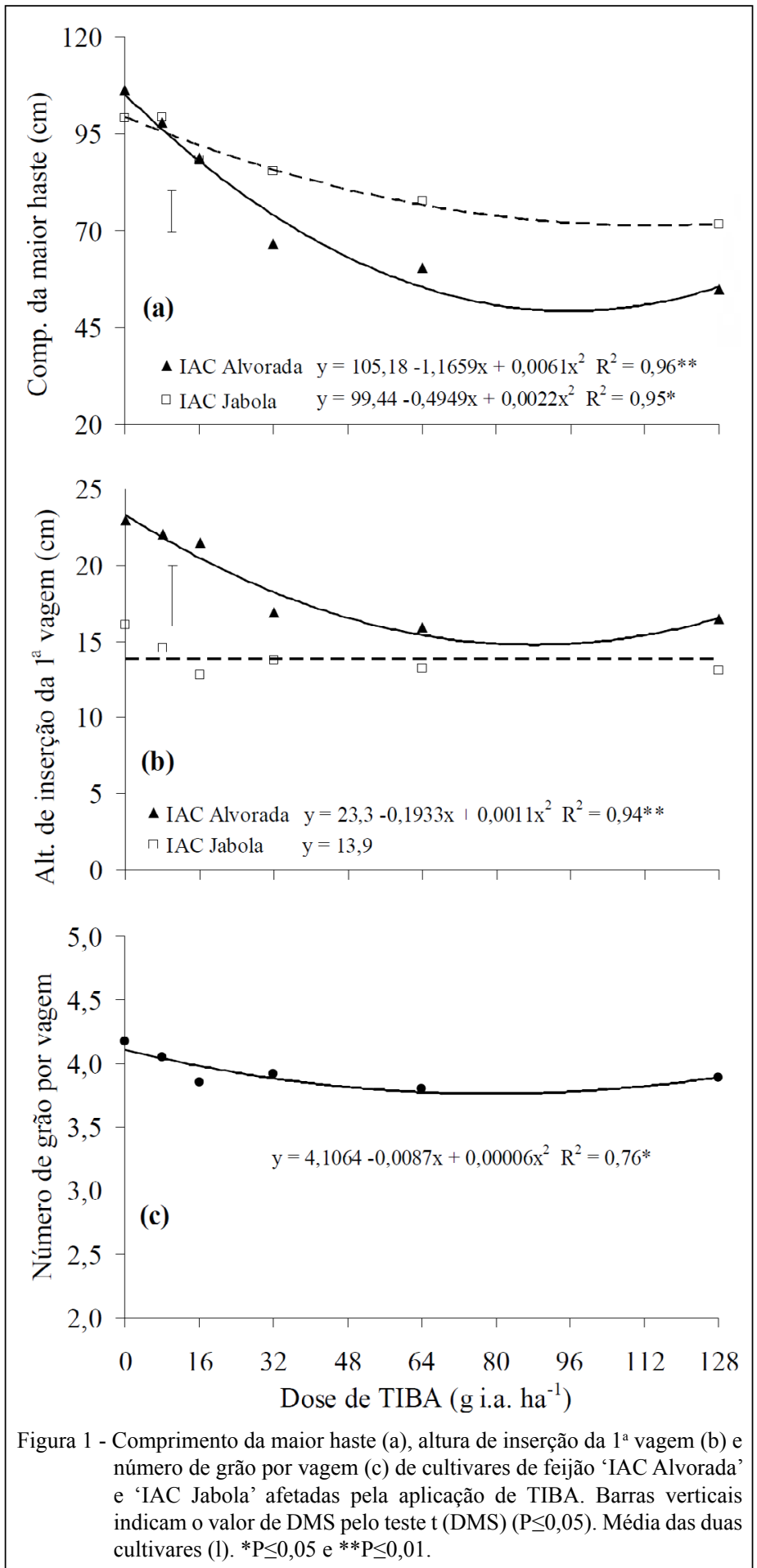

das plantas e aumentou o crescimento das estruturas reprodutivas, sem alterar a produção de MS total destas (TANNER \& AHMED, 1974). Na cultivar 'IAC Jabola', a área foliar e o acúmulo de MS na parte aérea foram maiores em decorrência do maior porte das plantas, tendo em vista que plantas mais altas possuem maior número de ramificações e de folhas (Tabela 1).

A altura de inserção da primeira vagem foi afetada pela interação cultivar x dose (Tabela 1). A 
aplicação de TIBA diminuiu a altura de inserção da primeira vagem da cultivar 'IAC Alvorada' em $8,2 \mathrm{~cm}$ até a dose de $88 \mathrm{~g} \mathrm{ha}^{-1}$, mas, na cultivar 'IAC Jabola', as altas doses de TIBA reduziram o comprimento da maior haste sem diminuir significativamente a altura das vagens (Figuras 1a e 1b). Nas menores doses de TIBA, a altura de inserção da primeira vagem foi maior na cultivar 'IAC Alvorada', mas, nas doses acima de $16 \mathrm{~g} \mathrm{ha}^{-1}$, não houve diferença entre as cultivares. Apesar de, nas doses mais elevadas de TIBA, a altura de inserção da primeira vagem da cultivar 'IAC Alvorada' ter sido reduzida, as plantas dessa cultivar tornaram-se mais compactas, uma vez que a hastes ficaram menores que as da cultivar 'IAC Jabola' e as primeiras vagens inseridas na mesma altura $(14 \mathrm{~cm})$ (Figuras 1a e 1b). Isso é um resultado interessante, porque plantas compactas com ramos curtos podem melhorar a aeração da cultura e beneficiar aplicações de defensivos, apesar de que a presença de vagens muito próximas do solo pode dificultar a colheita mecanizada (SILVA et al., 2008).

Houve efeito isolado apenas do fator cultivar sobre o número de ramos por planta, população final de plantas e massa de 100 grãos (Tabela 1). Na cultivar 'IAC Jabola', o número de ramos por planta e a massa de 100 grãos foi maior, mas a população final de plantas foi menor que na cultivar 'IAC Alvorada' (Tabela 1). Isso mostra que a cultivar 'IAC Jabola' compensou o menor número de planta por área, aumentando o porte das plantas (hastes maiores e com maior número de ramificações), o que refletiu em plantas com maior acúmulo de MS e com grãos de maior massa.

$\mathrm{O}$ número de vagens por planta não foi afetado pelos fatores estudados (Tabela 1). A aplicação de TIBA afetou o número de grãos por vagem, que diminuiu ligeiramente até a dose estimada de $73 \mathrm{~g}$ ha $^{-1}$ (Tabela 1). Em média, a aplicação de TIBA reduziu em até $10 \%$ o número de grãos por vagem do feijoeiro. Em soja, estudos demonstram que o TIBA pode aumentar o número de grãos por planta e reduzir o tamanho dos grãos, gerando um efeito de compensação que não altera a produtividade de grãos (HICKS et al., 1967), mas também há relatos de que esse regulador pode diminuir o número de grãos por planta, sem alterar a massa destes (CASTRO \& MORAES, 1981).

A produtividade de grãos não foi influenciada pelos fatores estudados (Tabela 1). Isso indica que a redução de $10 \%$ no número de grãos por vagem, proporcionada pela aplicação de TIBA (Figura 1c), não foi suficiente para alterar a produtividade do feijoeiro, possivelmente, pelo fato de o regulador não ter tido também algum pequeno efeito em outros componentes da produção. Além disso, a menor população de plantas da cultivar 'IAC Jabola' foi compensada pelo maior desenvolvimento das plantas, também não havendo diferenças entre as cultivares. Os resultados indicam que, apesar da aplicação de TIBA ter modificado a arquitetura das plantas de feijão, não reduziu a área foliar e não alterou a produção de fotoassimilados e a produtividade de grãos. Em feijoeiro, a aplicação de paclobutrazol, um inibidor da síntese de giberelina, diminuiu o comprimento das plantas, mas afetou negativamente a produtividade de grãos (GITTI et al., 2012). Em estudo com os reguladores cloreto de mepiquat, cloreto de clormequat, cloreto de clorocolina e etiltrinexapac nas cultivares de feijão 'Pérola' e 'IAPAR-81', observou-se que apenas o regulador cloreto de clorocolina reduziu a altura das plantas, mas nenhum dos produtos interferiu na produtividade de grãos (SOUZA et al., 2010). Em soja, a aplicação de TIBA também reduziu a altura das plantas sem interferir na produtividade de grãos (CATO \& CASTRO, 2006). Porém, há estudos que indicam que a aplicação de TIBA pode até aumentar a produtividade de grãos da soja quando as condições são favoráveis ao crescimento vegetativo da cultura, caso contrário a produtividade se mantém inalterada (TANNER \& ASHMED, 1974).

\section{CONCLUSÃO}

A aplicação de TIBA reduziu o comprimento da maior haste de ambas as cultivares, até a dose média estimada de $100 \mathrm{~g} \mathrm{ha}^{-1}$ de TIBA. A altura de inserção da primeira vagem foi reduzida apenas na cultivar 'IAC Alvorada' até a dose de $88 \mathrm{~g}$ ha $^{-1}$ de TIBA. A aplicação de TIBA reduziu em 10\% o número de grãos por vagem. A utilização de TIBA não afetou a produtividade de grãos, sendo uma alternativa para diminuir o porte das plantas de feijão.

\section{AGRADECIMENTOS}

Ao Conselho Nacional de Desenvolvimento Científico e Tecnológico (CNPq), pela concessão de bolsa de Produtividade em Pesquisa ao primeiro autor.

\section{REFERÊNCIAS}

AMBROSANO, E.J. et al. Leguminosas e oleaginosas. In: RAIJ, B. van. (Eds.). Recomendações de adubação e calagem para o Estado de São Paulo. Campinas: Instituto Agronômico de Campinas, 1997. p.189-204. (Boletim Técnico, 100). 
ANDRADE, J.P.R. et al. Controle de crescimento do feijoeiro semeado no verão/outono com aplicação do fungicida propiconazol. In: SEMINÁRIO DE INICIAÇÃO CIENTÍFICA E TECNOLÓGICA, 10., 2013, Belo Horizonte, MG. Anais... Belo Horizonte: EPAMIG, 2013. 5p

BASTIDAS, R.G.; BUITRAGO, G.L.A. Response of soybean to the application of triiodobenzoic acid (TIBA). Acta Agronómica, v.22, n.1, p.25-31, 1972.

BURTON, J.C.; CURLEY, R.L. Influence of triiodobenzoic acid on growth, nodulation and yields of inoculated soybeans. Agronomy Journal, v.58, n.4, p.406-408, 1966. Disponível em: <https://www. agronomy.org/publications/aj/abstracts/58/4/AJ0580040406>. Acesso em: 28 fev. 2015. doi:10.2134/agronj1966.00021962005800040013x.

CARBONELL, S.A.M. et al. 'IAC-Alvorada' and 'IACDiplomata': new common bean cultivars. Crop Breeding and Applied Biotechnology, v.8, n.2, p.163-166, 2008. Disponível em: $<$ http://www.sbmp.org.br/cbab/siscbab/uploads/bd6b9df0-168c8e69.pdf>. Acesso em: 02 mar. 2015. doi: 10.12702/1984-7033. v08n02a10.

CASTRO, P.R.C.; MORAES, R.S. Ação de fitoreguladores na produtividade da soja cultivar 'Davis'. Anais da Escola Superior de Agricultura Luiz de Queiroz, v.38, n.1, p.127-138, 1981. Disponível em: <http://www.scielo.br/scielo.php?pid=S007112761981000100012\&script $=$ sci arttext $>$. Acesso em: 20 fev. 2015. doi: 10.1590/S0071-12761981000100012.

CATO, S.C.; CASTRO, P.R.C. Redução da altura de plantas de soja causada pelo ácido 2,3,5-triiodobenzóico. Ciência Rural, v.36, n.3, p.981-984, 2006. Disponível em: <http://www.scielo.br/ scielo.php?script $=$ sci_arttext\&pid $=$ S0103-84782006000300041>. Acesso em: 20 fev. 2015. doi: 10.1590/S0103-84782006000300041.

CHIORATO, A.F. et al. 'IAC Jabola' and 'IAC Esperança': common bean cultivars for market niches. Crop Breeding and Applied Biotechnology, v.9, n.2, p.199-201, 2009. Disponível em: <http:// www.sbmp.org.br/cbab/siscbab/uploads/c8129491-875c-7779.pdf>. Acesso em: 02 mar. 2015. doi: 10.12702/1984-7033.v09n02a14

FERREIRA, M.M.R. Reguladores vegetais e nitrogênio em cobertura em feijoeiro de inverno no sistema plantio direto. Revista Agrarian, v.6, n.21, p.268-280, 2013. Disponível em: $<$ http://www.periodicos.ufgd.edu.br/index.php/agrarian/article/ viewArticle/2207>. Acesso em: 18 fev. 2015.

GELDNER, N. et al. Auxin transport inhibitors block PINT cycling and vesicle trafficking. Nature, v.413, n.6854, p.425-428, 2001. Disponível em: <http://www.nature.com/nature/journal/ v413/n6854/full/413425a0.html>. Acesso em: 20 fev. 2015. doi: $10.1038 / 35096571$

GITTI, D.C. et al. Aplicação de paclobutrazol e doses de nitrogênio em feijão de inverno cultivado em sistema plantio direto. Scientia Agraria Paranaensis, v.11, n.3, p.35-46, 2012. Disponível em: $<$ http://e-revista.unioeste.br/index.php/scientiaagraria/article/ view/5678/5462>. Acesso em: 21 fev. 2015.

HICKS, D.R. et al. Response of soybeans to TIBA (2,3,5-triiodobenzoic acid) and high-fertility levels. Crop Science, v.7, n.4, p.397-398, 1967. Disponível em: <https://www.agronomy.
org/publications/cs/abstracts/7/4/CS0070040397>. Acesso em: 19 fev. 2015. doi: 10.2135/cropsci1967.0011183X000700040037x.

KOLKMAN, J.M.; KELLY, J.D. Agronomic traits affecting resistance to white mold in common bean. Crop Science, v.42, n.3, p.693-699, 2002. Disponível em: <https://www.crops.org/ publications/cs/abstracts/42/3/693>. Acesso em: 18 fev. 2015. doi: $10.2135 /$ cropsci2002.6930.

RADEMACHER, W. Growth retardants: effects on gibberellin biosynthesis and other metabolic pathways. Annual Review of Plant Physiology and Plant Molecular Biology, v.51, n.1, p.501531, 2000. Disponível em: <http://www.annualreviews.org/doi/ abs/10.1146/annurev.arplant.51.1.501?url_ver=Z39.88-2003\&rfr $\mathrm{dat}=\mathrm{cr}$ pub\%3Dpubmed $\& \mathrm{rfr}$ id $=$ ori $\% 3$ Arid $\% 3$ Acrossref. org\&journalCode=arplant.2>. Acesso em: 25 fev. 2015. doi: 10.1146/annurev.arplant.51.1.501.

RAIJ, B. van. et al. Análise química para avaliação da fertilidade de solos tropicais. Campinas: Instituto Agronômico, 2001. 284p.

SANTOS, H.G. et al. (Eds.). Sistema brasileiro de classificação de solos. 2.ed. Rio de Janeiro : Embrapa Solos, 2006. 306p.

SILVA, R.P. et al. Desempenho operacional do conjunto tratorrecolhedora de feijão. Ciência Rural, v.38, n.5, p.1286-1291, 2008. Disponível em: $<$ http://www.scielo.br/scielo.php?script=sci_arttex t\&pid=S0103-84782008000500013>. Acesso em: 26 fev. 2015. doi: $10.1590 / \mathrm{S} 0103-84782008000500013$.

SINGH, S.P. Broadening the genetic base of common bean cultivars: a review. Crop Science, v.41, n.6, p.1659-1675, 2001. Disponível em: <https://www.crops.org/publications/cs/ abstracts/41/6/1659>. Acesso em: 26 fev. 2015. doi: 10.2135/ cropsci2001.1659.

SOUZA, C.A. et al. Atributos morfométricos e componentes da produção do feijoeiro sob efeito de redutores de crescimento. Científica, v.38, n.1/2, p.30-37, 2010. Disponível em: <http:// www.cientifica.org.br/index.php/cientifica/article/view/220>. Acesso em: 27 fev. 2015. doi: 10.15361/1984-5529.2010v38 $\mathrm{n} 1 \% 2 \mathrm{~F} 2 \mathrm{p} 30+-+38$.

TANNER, J.W.; AHMED, S. Growth analysis of soybeans treated with TIBA. Crop Science, v.14, n.3, p.371-374, 1974. Disponível em: $\quad<$ https://www.crops.org/publications/cs/abstracts/14/3/CS01 40030371 ?access $=0 \& v i e w=$ pdf $>$. Acesso em: 27 fev. 2015. doi: 10.2135/cropsci1974.0011183X001400030009x.

VALÉRIO, C.R. et al. Comportamento das cultivares de feijão 'Aporé', 'Carioca' e 'Pérola' em diferentes populações de plantas e espaçamentos entre linhas. Ciência e Agrotecnologia, v.23, n.3, p.515-528, 1999. Disponível em: <http://www.editora.ufla.br/ index.php/revistas/ciencia-e-agrotecnologia/artigos-publicados/10volumes-revista/45-vol23numero3 > . Acesso em: 28 fev. 2015.

WAX, L.M.; PENDLETON, J.W. Influence of 2,3,5 - triiodobenzoic acid (TIBA) on soybeans planted in different cultural systems. Agronomy Journal, v.60, n.4, p.425-427, 1968. Disponível em: $<$ https://www.agronomy.org/publications/aj/abstracts/60/4/AJ06 00040425 ? access $=0 \&$ view $=$ pdf $>$. Acesso em: 28 fev. 2015. doi: 10.2134/agronj1968.00021962006000040029x. 